\title{
PLURALISMO TEÓRICO NA GESTÃO ESTRATÉGICA: A COMPREENSÃO DA VANTAGEM COMPETITIVA A PARTIR DA HARMONIZAÇÃO DE PERSPECTIVAS ANTAGÔNICAS ${ }^{1}$
}

\author{
THEORETICAL PLURALISM IN THE STRATEGICAL MANAGEMENT: THE \\ UNDERSTANDING OF THE COMPETITIVE ADVANTAGE FROM THE \\ HARMONIZATION OF ANTAGONISTIC PERSPECTIVES
}

\begin{abstract}
Karla Simoni Oening ${ }^{2}$
RESUMO: Ambientes competitivos impõem contingências às organizações que colocam em evidência as limitações das premissas estratégicas tradicionais, fundamentadas no caráter estático, formal e normativo. Além disso, as abordagens teóricas de gestão estratégica têm sido apresentada na literatura de forma concorrente e fragmentada, motivo pelo qual, apesar de enriquecerem a base do conhecimento, pouco contribui para interpretar as fontes de obtenção e de manutenção da vantagem competitiva e explicar as razões de algumas empresas apresentarem performances superiores a outras. Partindo dessas premissas e visando colaborar para o desenvolvimento do conhecimento em estratégia no plano teórico e prático, o presente artigo se propõe a revisar as perspectivas teóricas de Gestão Estratégica e argumenta em favor de uma abordagem pluralista e integrativa que harmonize as quatro vertentes de análise, de forma contemplar a análise interna (Visão Baseada em Recursos), e a externa (Análise Estrutural da Indústria), à luz de uma visão dinâmica dos recursos, competências e habilidades (Teorias das Competências Dinâmicas) e de uma compreensão da concorrência e dos ambientes competitivos como constantemente mutantes (Processos de Mercado).
\end{abstract}

PALAVRAS-CHAVE: vantagem competitiva, recursos, ambientes competitivos.

ABSTRACT: Competitive environments impose contingencies to the organizations that place in evidence the limitations of the traditional strategical premises, based on the static, formal and normative character. Moreover, the theoretical boardings of strategical management have been presented in the literature of divergent and broken up form, reason for which, although to enrich the base of the knowledge, little contribute to interpret the sources of attainment and maintenance of the competitive advantage and to explain the reasons of some companies to present superior performances to others. Leaving of these premises and aiming at to collaborate for the development of the knowledge in strategy in the theoretical and practical plan, the present article if considers to revise the perspectives theoretical of Strategical Management and argues for a pluralista and integrativa boarding that harmonizes the four sources of analysis, form to contemplate the internal analysis (Vision Based on Resources), and the external one (Structural Analysis of the Industry), to the light of a dynamic vision of the resources, abilities and abilities (Theories of the Dynamic Abilities) and of an understanding of the competition and competitive environments as constantly mutants (Processes of Market).

KEYWORDS: competitive advantage, resources, competitive environments.

\footnotetext{
${ }^{1}$ Artigo Recebido em 10.12.2008. Revisado por pares em 15.04.2010. Recomendado em 15.04.2010 por Leomar dos Santos Editor. Publicado em 08.09.2010.

Organização Responsável pelo periódico: Universidade regional de Blumenau - FURB - www.furb.br/rn
}

\footnotetext{
${ }^{2}$ Universidade Federal de Santa Catarina - UFSC - koening@eletrosul.gov.br
} 


\section{INTRODUÇÃO}

Ambientes competitivos e em processo de mudança compelem organizações de praticamente todos os setores a reavaliarem as suas estratégias. Vantagens competitivas tornam-se obsoletas pela dinâmica da competição, submetendo-as a um elevado grau de concorrência que apontam para a necessidade de rápida reação (D’AVENI, 1995).

$\mathrm{Na}$ esfera acadêmica parece haver consenso de que os conceitos e ferramentas de análise que formam a mainstream da literatura estratégica necessitam de uma reavaliação para atender à complexidade dos ambientes competitivos (HAMEL, PRAHALAD, 1995) e que as contingências impostas por este contexto colocam em evidência as fraquezas das premissas estratégicas tradicionais, que defendem o controle hierárquico, o planejamento formal e a análise industrial (VOLBERDA, 2004).

A despeito de uma série de contribuições teóricas, conceituais e empíricas, a área da estratégia está repleta de prescrições e de diretrizes concorrentes que não conseguem responder a preocupação central dos gestores e da teoria da Gestão Estratégica, que é desvendar como as organizações criam e sustentam vantagens competitivas, ou seja, de que maneira se distinguem dos seus concorrentes e conseguem conquistar mercados de forma duradoura e sustentável (RUMELT et al., 1994).

Os modelos teóricos tradicionais têm se dividido em duas correntes antagônicas em termos de origem de vantagem competitiva: uma que prioriza a compreensão da vantagem competitiva como fator exógeno à organização, decorrente da estrutura da indústria, do posicionamento, da dinâmica da concorrência e do mercado; e outra que, em contraponto, reconhece as competências, capacidades e habilidades como a base do conhecimento produtivo e organizacional, explicando a vantagem competitiva principalmente por intermédio de fatores internos às firmas. Embora divergentes em suas orientações particulares, ambas as visões estão fundamentadas nos pressupostos neoclássicos de comportamento econômico, na racionalidade, estabilidade e previsibilidades dos mercados.

De acordo com Vasconcelos e Cyrino (2000), essas pesquisas comumente focalizam o “conteúdo" das estratégias e se utilizam de abordagens metodológicas dirigidas à verificação empírica de hipóteses generalizáveis. Devido ao caráter estático das suas análises e a carência de exame do ambiente, cuja influência é determinante para o comportamento das organizações, tanto os paradigmas outside-in quanto os inside-out esbarram em uma lacuna epistemológica que reflete no distanciamento entre a teoria e a prática estratégica (LEITE, PORSSE, 2003).

De forma a tentar extinguir tal impasse, contribuição relevante vem sendo apresentada pelas abordagens voltadas ao comportamento do ambiente competitivo em longo prazo e a natureza da mudança organizacional, quais sejam: a teoria de processos de mercado e a teoria das capacidades dinâmicas. O enfoque aqui está nas características dinâmicas da obtenção da vantagem competitiva, como desequilíbrio, descontinuidade, inovação e os processos internos de adaptação, inovação e aprendizagem, utilizando, preferencialmente, métodos qualitativos com o objetivo de entender e explicar, no seu contexto, a natureza e a dinâmica dos processos de mudança organizacional.

Apesar de enriquecerem a base do conhecimento, nenhuma dessas quatro vertentes teóricas, vistas isoladamente, consegue explicar como as empresas alcançam vantagens competitivas sustentáveis, pois, do mesmo modo que os recursos da empresa - seus ativos, capacidades e habilidades - condicionam a formulação da estratégia, importante também é a coordenação destes com a dinâmica dos ambientes competitivos. Ou seja, a desconsideração de qualquer um desses aspectos acarretaria em uma análise fragmentada e parcial, distante da realidade das organizações. 


\section{PLURALISMO TEÓRICO NA GESTÃO ESTRATÉGICA: A COMPREENSÃO DA VANTAGEM COMPETITIVA A PARTIR DA HARMONIZAÇÃO DE PERSPECTIVAS ANTAGÔNICAS}

Apesar das consideráveis diferenças teóricas e metodológicas, a possibilidade de convergência conceitual e metodológica dessas abordagens justifica-se especialmente em razão da necessidade de compreender e influenciar a mudança cada vez mais freqüente nas organizações em resposta às contínuas mudanças e incertezas do ambiente. Além disso, esta ausência de previsibilidade e estabilidade coloca em evidência as limitações teóricas e práticas das premissas estratégicas tradicionais e apontam para a necessidade de uma redefinição de seu escopo a fim de responder as contingências ambientais.

A partir do reconhecimento do aumento da complexidade ambiental (e da sua influência sobre o comportamento das firmas) e da importância dos processos e recursos organizacionais, o presente artigo defende que a convergência conceitual e metodológica dessas visões, contemplando tanto a análise interna com a externa, poderia favorecer uma compreensão mais abrangente da maneira pela qual a empresa cria valor num todo integrado, pois parte-se da compreensão que a estratégia corporativa notável e que diferencia uma empresa das demais é representada pela conversão dos recursos e atividades combinadas em produtos ou serviços voltados especificamente ao seu setor de atuação.

\section{PERSPECTIVAS PARA ANÁLISE DA VANTAGEM COMPETITIVA}

A vantagem competitiva, isto é, a ocorrência de níveis de desempenho econômico acima da média do mercado em conseqüência das estratégias adotadas pelas empresas, é explicada de forma diferenciada por quatro correntes do pensamento sobre estratégia empresarial (Vasconcelos, Cyrino, 2000), que estão representadas na Figura 01.

A primeira vertente propõe uma classificação de acordo com a origem da vantagem competitiva. De um lado, estão as teorias orientadas por uma visão de fora para dentro da organização (paradigma outside-in), para as quais a vantagem competitiva é compreendida como fator exógeno a organização, decorrente da estrutura da indústria, da dinâmica da concorrência e do mercado. De outro, estão os trabalhos que consideram a performance superior como explicada principalmente por meio de fatores internos às firmas (paradigma inside-out).

O segundo eixo de análise identifica as abordagens teóricas de acordo as suas premissas com relação à concorrência e ao ambiente competitivo. O desdobramento se faz entre os estudos que possuem uma visão estrutural da concorrência, estática e baseada na noção de equilíbrio econômico, dos que enfocam aspectos dinâmicos e mutáveis da concorrência.

\begin{tabular}{|c|c|c|c|}
\hline \multirow{2}{*}{$\begin{array}{c}\text { ORIGEM DA } \\
\text { VANTAGEM } \\
\text { COMPETITIVA }\end{array}$} & $\begin{array}{l}\text { Fatores exógenos à } \\
\text { organização }\end{array}$ & $\begin{array}{c}\text { ANÁLISE ESTRUTURAL } \\
\text { DA INDÚSTRIA } \\
\text { Análise de Posicionamento }\end{array}$ & $\begin{array}{c}\text { PROCESSOS DE } \\
\text { MERCADO } \\
\text { Teoria dos Processos do Mercado }\end{array}$ \\
\hline & $\begin{array}{l}\text { Fatores endógenos à } \\
\text { organização }\end{array}$ & $\begin{array}{c}\text { RECURSOS E } \\
\text { COMPETÊNCIAS } \\
\text { Visão Baseada em Recursos } \\
\end{array}$ & $\begin{array}{c}\text { CAPACIDADES } \\
\text { DINÂMICAS } \\
\text { Teoria das Capacidades Dinâmicas }\end{array}$ \\
\hline & & Estático & Dinâmico \\
\hline & & \multicolumn{2}{|c|}{$\begin{array}{c}\text { COMPORTAMENTO DO } \\
\text { AMBIENTE COMPETITIVO }\end{array}$} \\
\hline
\end{tabular}

Figura 01: As perspectivas de análise da vantagem competitiva

Fonte: Adaptado de Vasconcelos e Cyrino (2000)

\subsection{A Vantagem Competitiva na perspectiva da Análise Estrutural da Indústria}


Um das contribuições mais significativas para a área da estratégia é a apresentada por Porter (1980), que analisa a competição sob o foco do posicionamento dentro de uma determinada estrutura industrial. Enraizada no paradigma estrutura-conduta-desempenho da organização industrial, proposta por Mason (1949) e Bain (1959), originalmente desenvolvido dentro de uma perspectiva de regulamentação de indústrias não competitivas (Ghemawat, 2000), a abordagem das forças competitivas discute a respeito das ações da firma destinadas a criar posições defensivas contra as forças competitivas - que vão além da análise da concorrência, uma vez que, em essência, a formulação da estratégia para esta abordagem consiste em enfrentar a competição.

Para Porter (1986) a competição em um determinado setor se encontra arraigada na sua economia adjacente e depende de cinco forças básicas, quais sejam: ameaça de novos entrantes, ameaça de produtos substitutos, poder de negociação dos fornecedores, poder de negociação dos compradores e a rivalidade entre as empresas componentes da própria indústria. A dinâmica coletiva dessas cinco forças é que determina as perspectivas de lucros do setor. Portanto, o objetivo do estrategista é encontrar uma posição na qual a empresa seja capaz de melhor se defender contra essas cinco forças ou de influenciá-las a seu favor.

O desempenho de qualquer empresa em um determinado ramo de atividade é atribuído ao desempenho médio de todos os concorrentes do setor e ao desempenho relativo da empresa no setor, acima ou abaixo da média (PORTER, 1998). Conseqüentemente, a vantagem competitiva depende do alcance de uma posição estratégica distinta, que são sustentáveis em razão da seleção entre duas opções excludentes, denominadas estratégias genéricas: a liderança de custo e diferenciação. A vantagem competitiva, dessa forma, resulta da capacidade da organização de realizar eficientemente o conjunto de atividades necessárias para obter um custo mais baixo que os concorrentes ou de organizar essas atividades de forma única, capaz de gerar valor diferenciado para os compradores.

O custo mais baixo funciona como mecanismo de defesa contra a rivalidade de seus concorrentes, uma vez que, quando pressionada por fornecedores poderosos, a empresa de custo mais baixo terá mais fôlego para continuar na indústria do que seus concorrentes, que também estão sujeitos à pressão desses fornecedores, enquanto a estratégia de diferenciação estratégia oferece defesa contra as forças do ambiente no que se refere à lealdade e a diminuição da sensibilidade ao preço isolam, em maior ou menor grau, a empresa da rivalidade de seus concorrentes. Similarmente, o poder dos compradores também diminui, uma vez que eles não encontrarão no mercado outro produto com as mesmas características.

Em suma, para a análise estrutural da indústria a capacidade de atuação da empresa é limitada pelo meio externo, cuja estrutura é de fundamental importância. O desafio dos gestores reside, dessa forma, em encontrar uma posição que ofereça segurança contra os ataques dos competidores existentes e potenciais e contra o poder de barganha dos consumidores e fornecedores.

\subsection{A Vantagem Competitiva segundo a Visão Baseada em Recursos}

As raízes da Visão Baseada em Recursos são atribuídas às pesquisas de Penrose (1959), que se concentraram na discussão do crescimento da empresa, adotando uma perspectiva distinta da tradicional discussão de posicionamento inspirada na Economia Industrial, focalizando sua atenção sobre a heterogeneidade entre as empresas pertencentes a uma mesma indústria, explicando os motivos pelos quais elas se diversificam, de seus compostos únicos de recursos e capacidades que alicerçam as bases sobre as quais uma vantagem competitiva pode ser conquistada. 


\section{PLURALISMO TEÓRICO NA GESTÃO ESTRATÉGICA: A COMPREENSÃO DA VANTAGEM COMPETITIVA A PARTIR DA HARMONIZAÇÃO DE PERSPECTIVAS ANTAGÔNICAS}

Em sua concepção básica, a Visão Baseada em Recursos sustenta que as empresas com estruturas organizacionais e sistemas de coordenação de atividades superiores são lucrativas porque se apropriam de rendimentos extraordinários oriundos da escassez no mercado de recursos específicos da firma. Assim, uma estratégia focada nos recursos e competências próprios da empresa pode consolidar uma base estável para definir a identidade da empresa e para uma formulação estratégica mais durável, representando as fontes primárias de lucro da empresa e abastecendo o direcionamento estratégico da empresa (GRANT, 1991).

De acordo com essa abordagem, portanto, a diferença de desempenho entre as empresas, ou melhor, a obtenção da vantagem competitiva, é explicada pela heterogeneidade de recursos. Assume, portanto, que são as diferenças em recursos o cerne do problema estratégico. Isso significa que a fonte básica para a vantagem competitiva são os recursos e competências desenvolvidos e controlados pelas firmas. Em outros termos, de acordo com Leite e Porsse (2003), são as imperfeições do mercado que possibilitam a obtenção de desempenho acima da média do mercado, sendo os recursos essenciais para as empresas conquistarem vantagem competitiva. Assim, a vantagem competitiva da empresa deriva do acúmulo de ativos e de capacidades estratégicas (HAFEEZ et al., 2002).

Porém, nem todos os recursos têm o potencial de oferecer uma vantagem competitiva sustentável para a empresa. A vantagem no mercado, dizem os defensores dessa perspectiva (WERNERFELT, 1984, BARNEY, 1991, GRANT, 1991), somente pode ser criada e sustentada quando se baseia em recursos (físicos, financeiros e também intangíveis e invisíveis) únicos, raros, valiosos, inimitáveis e para os quais os concorrentes não podem encontrar substitutos e cuja mobilidade e/ou negociação fosse imperfeita. As decisões sobre a combinação e alocação de recursos podem determinar o sucesso da empresa (PENROSE, 1959), desde que haja uma estratégia apropriada para a sua alocação (BARNEY, 1991).

Peteraf (1993) enfatiza que uma vantagem competitiva sustentável requer que a condição de heterogeneidade da empresa seja preservada, o que só é possível se existir limites ex post para a competição. Segundo a autora, a visão baseada em recursos tem focalizado dois atributos críticos que limitam a competição ex post: o recurso deve ser imperfeitamente imitável e imperfeitamente substituível. Outras condições inerentes a um recurso com potencial para conferir uma vantagem competitiva são seu valor para o cliente e sua característica de raridade (BARNEY, 1991).

Nessa ênfase da estratégia em termos de “oferta”, a vantagem competitiva é definida como sendo a implementação de uma estratégia que agregue valor e gere benefícios para uma empresa, sem que outra concorrente simultaneamente a faça (BARNEY, 1991). Ao reconhecer as organizações como uma coleção de ativos tangíveis e intangíveis e competências, supõe que quanto melhor e mais apropriado para o negócio for o conjunto de recursos, mais a organização detentora deste conjunto estará apta a obter vantagem competitiva (COLLINS, MONTGOMERY, 2000).

\subsection{Processos de Mercado e a Vantagem Competitiva}

Importante contribuição às teorias da vantagem competitiva concentra-se na dinâmica da empresa, dos mercados e da concorrência, enfatizando os processos de inovação, onde os fenômenos do mercado esperados - tais como a inovação e os novos concorrentes - são responsáveis pelas diferenças de performance das firmas (VASCONCELOS, CYRINO, 2000). A teoria de processos de mercado está preocupada com a seqüência de eventos que ocorrem no mercado, que podem ou não levar a um estado de equilíbrio.

Esta teoria se fundamenta na constatação de que algumas empresas conseguem manter uma performance superior apesar dos contínuos esforços de imitação dos concorrentes de 
suas estratégias, produtos, métodos de produção e esquemas de distribuição. A diferença de performance é, dessa forma, atribuída a fatores inobserváveis, invisíveis, que se escondem por trás dos fatores objetivamente mensuráveis dos processos de produção. Duas correntes teóricas tratam das características dinâmicas da economia industrial. A primeira é a intitulada escola austríaca, que se concentra nas conseqüências econômicas da inovação e da mudança tecnológica; e a segunda enfoca os recursos diferentes empregados pelas firmas na competição. Para ambas as teorias, o desequilíbrio é a situação habitual, negando a tendência ao equilíbrio dos sistemas econômicos, advogada pela teoria microeconômica neoclássica (CONNER, 1991; KIRZNER, 1997).

A escola austríaca cria uma visão da economia baseada nos conceitos de inovação e em um estado de desequilíbrio contínuo (Jacobson, 1992) e está focada nos processos de mudança tecnológica e da estrutura social, nas dinâmicas de inovação, na entrada de novos concorrentes. Enquanto a economia neoclássica desenvolve um conceito de equilíbrio estático e estável, nesta escola o equilíbrio é dinâmico e instável. O mercado, sem nunca atingir equilíbrio, é descrito como um processo de descoberta interativa de novas oportunidades de negócios (HAYEK, 1944).

A obtenção de lucros extraordinários se dá por meio deste processo de descoberta interativa, da inovação, da descoberta de oportunidades e da mobilização pioneira de recursos. Por outro lado, a maior lucratividade do inovador atrai imitadores e, em pouco tempo, o diferencial de desempenho é corroído pela competição. Contudo, a inovação constante e a ação empreendedora estão permanentemente criando fontes de heterogeneidade entre as firmas, apesar dos mecanismos de imitação atuarem no sentido inverso (JACOBSON, 1988; KIRZNER, 1997).

A dinâmica da estratégia empresarial e da heterogeneidade de desempenho das firmas pode ser explicada pela especificidade das firmas, isto é, sua diferença intrínseca. Segundo Chamberlin (apud Brito, Vasconcelos, 2004), a competição em uma indústria se dá entre firmas com recursos diferentes, ainda que ocasionalmente equivalentes. Alguns desses recursos específicos podem representar vantagens importantes para certas firmas em condições específicas de mercado. Como os recursos das firmas são muitas vezes parcialmente equivalentes, a competição entre as firmas toma forma de competição monopolística, gerando uma forma de competição indireta por substituição.

\subsection{Capacidades Dinâmicas e a Obtenção da Vantagem Competitiva}

A abordagem das Capacidades Dinâmicas se fundamenta conjuntamente na abordagem de Chamberlin (apud BRITO, VASCONCELOS, 2004) e na escola austríaca (CONNER, 1991; KIRZNER, 1997). A partir da compreensão de capacidade dinâmica como a habilidade de integrar, coordenar, construir e reconfigurar competências internas e externas (TEECE et al., 1997) ou como rotinas resultantes da variação, seleção e retenção de comportamentos passados que visam posicionar adequadamente os recursos face às mudanças no ambiente (WINTER, 2003), a Teoria das Capacidades Dinâmicas articula a importância de concomitantemente explorar o ambiente interno e de extrapolar os limites organizacionais para a obtenção de vantagem competitiva. A habilidade da empresa para se organizar como um sistema de aprendizagem contribui para a construção de uma estratégia mais dinâmica e condizente com as características do atual cenário competitivo (GHEMAWAT, 1991).

Para Nelson e Winter (1982), a organização é um conjunto interdependente de rotinas operacionais e administrativas que evoluem lentamente, inserindo as capacidades dinâmicas nos processos de rotina resultantes da variação, seleção e retenção de comportamentos passados. A premissa central continua sendo os recursos valiosos, raros, inimitáveis e não 


\section{PLURALISMO TEÓRICO NA GESTÃO ESTRATÉGICA: A COMPREENSÃO DA VANTAGEM COMPETITIVA A PARTIR DA HARMONIZAÇÃO DE PERSPECTIVAS ANTAGÔNICAS}

substituíveis, como na Visão Baseada em Recursos. Como as firmas integram, constroem e reconfiguram seus recursos, as capacidades dinâmicas podem ser compreendidas como um modelo estável de atividades coletivas, por meio do qual a empresa, sistematicamente, constitui e altera suas rotinas operacionais na tentativa de alcançar maior efetividade (ZOLLO, WINTER, 2002). Essas rotinas - modelos estáveis de comportamento que caracterizam reações organizacionais aos diferentes estímulos provenientes do ambiente interno ou externo, por estarem arraigadas na cultura da empresa, permitem que as rotinas estratégicas e organizacionais pelas quais as firmas adquirem uma nova configuração de recursos à medida que o mercado emerge, evolui e morre (EISENHARDT, MARTIN, 2000).

As capacidades dinâmicas estão inseridas nos processos organizacionais, nas rotinas operacionais e competências (AMIT, ZOTT, 2001). Esses recursos, tanto podem ser alterados pela experimentação que ocorre no interior da organização como pela imitação das melhores práticas dos concorrentes. Com o foco na renovação, a empresa gera novos ativos e adquire novas habilidades capazes de criar uma interface adequada para fazer frente aos necessários ajustes internos e às mudanças no mercado. A ênfase no ambiente interno da organização deriva da Visão Baseada em Recursos, enquanto a importância de explorar, concomitantemente, o ambiente externo evidencia a necessidade de extrapolar os limites organizacionais ante a complexidade e constante evolução do conhecimento, seu potencial impacto e real aproveitamento na performance empresarial.

Assim, a conectividade, interatividade e velocidade podem desencadear um novo ritmo à tomada de decisão e a execução geral das rotinas e dos processos da organização. $\mathrm{O}$ impulso desencadeado pelas discussões em torno das capacidades dinâmicas intensificou a corrida em busca de novas fontes de recursos. Assim, não basta, portanto, a organização dispor de recursos valiosos, raros, inimitáveis e insubstituíveis, como anunciado pela RBV, o mais importante é que ela possua capacidade de resposta no tempo, que gere inovações rápidas, associadas à capacidade gerencial de coordenar e realocar de forma efetiva as competências internas e externas da empresa, já que essas se modificam ao longo do tempo, tanto em razão de seus próprios esforços na solução de problemas quanto em função de eventos inesperados. A vantagem competitiva e a sua sobrevivência ao longo do tempo de uma empresa podem ser explicadas pela sua capacidade de criar e recriar continuamente novas competências, à medida que mudam as características do ambiente de negócios.

\section{Vertentes de Análise da Vantagem Competitiva: em busca de uma concepção integrativa e pluralística}

Os paradigmas da Análise Estrutural da Indústria e da Teoria Baseada em Recursos, ao não examinarem convenientemente o cenário dos negócios, pouco explicam sobre o desempenho da empresa, a obtenção e a sustentação das vantagens competitivas (SCHMALENSEE, 1985; RUMELT, 1991; VASCONCELOS, BRITO, 2004). Devido à natureza estática das suas análises, oferecem no máximo explicações teóricas ex post dos ambientes competitivos e dos recursos importantes estrategicamente (VASCONCELOS, CYRINO, 2000), sucumbindo em um impasse epistemológico que distancia a teoria da prática estratégica (HEENE, SANCHEZ apud LEITE, PORSSE, 2003).

Ambas as abordagens falham ao tentar responder a questões fundamentais para a Gestão Estratégica, quais sejam: Quais aspectos terão função central na manutenção da vantagem competitiva de uma organização? Serão os processos que determinam a vantagem competitiva de uma empresa os mesmos que lhe irão permitir a sobrevivência ao longo do tempo? É correto afirmar que as capacidades e competências de uma empresa permanecem estáticas ao longo do tempo? 
De fato, a concepção porteriana de estratégia como um processo controlado, consciente e deliberado (MINTZBERG et al., 2000), cujas posições genéricas identificáveis devem ser selecionadas com embasamento em uma análise mercadológica fundamentada no modelo das cinco forças, vem sendo amplamente criticada graças a sua compreensão de que a estratégia adequada deve se adaptar às condições vigentes, levando a uma impressão de que as empresas precisam mudar constantemente para atender às contingências ambientais, o que pode ser um fator limitador à capacidade da empresa de inovar, ingressar rapidamente em mercados emergentes ou alterar as escolhas dos clientes em mercados maduros (CARNEIRO et al., 1997). Além disso, por se fundamentar em pressupostos de racionalidade adjacentes aos da economia neoclássica, de equilíbrio e certeza (LEITE, PORSSE, 2003), resulta em um tipo de análise estática, conseqüentemente, distante da realidade das organizações.

A organização, portanto, é vista como desprovida de autonomia decisória e responde passivamente às mudanças no ambiente externo. Carneiro et al. (1997) consideram que a predominância exagerada na análise da indústria serve de fator limitador à capacidade da empresa de inovar, ingressar rapidamente em mercados emergentes ou alterar as escolhas dos clientes em mercados maduros. O caráter exógeno das forças ambientais no que diz respeito à determinação da dinâmica interna da empresa exige um esforço contínuo em termos de adaptação ex post. Por esse motivo, para Foss (1996) e Rumelt et al. (1991) o trabalho de Porter (1980) carece de debates mais consistentes voltados para as questões internas da empresa, como a estrutura organizacional, os recursos e a dimensão comportamental. De acordo com Grant (1991), a capacidade limitada de lidar com a volatilidade do ambiente externo, fazem as empresas - em busca de um senso estável de direção - voltarem a atenção para as suas capacidades internas.

As idéias apresentadas pela Visão Baseada em Recursos surgiram justamente em oposição a compreensão da análise da vantagem competitiva orientada para o exterior das organizações, alterando o referencial das causas da vantagem competitiva para a configuração interna dos recursos e competências das firmas. A ênfase se desloca para os processos por meio dos quais a vantagem competitiva é criada e sustentada, de forma que são os recursos disponíveis que orientam as decisões estratégicas e não o ambiente (como na Análise Estrutural da Indústria).

Ressalta Börner (apud WALTER et al., 2005), no entanto, que a Visão Baseada em Recursos, apesar de oferecer alternativas viáveis para a compreensão das implicações para decisões estratégicas, não sugere modelos de estratégia, o que pode ser uma obstáculo para a implementação de seus princípios. Além disso, ao privilegiar a determinação da estratégia "de dentro para fora”, essa visão ela atribui papel secundário ao ambiente na determinação da estratégia competitiva. Igualmente ao paradigma da Análise Estrutural da Indústria, a teoria dos recursos permanece, em geral, muito ligada às tradições neoclássicas de racionalidade, comportamento econômico, estabilidade e previsibilidade (FOSS, 1996).

A despeito das divergências entre as abordagens da Análise Estrutural da Indústria e da Visão Baseada em Recursos, que torna as duas visões concorrentes entre si sob determinados aspectos, a importância de se ponderar o dilema existente entre o posicionamento competitivo voltado para o mercado (PORTER, 1980) e a estratégia baseada nos recursos (BARNEY, 1991, 2001), foi preocupação já apresentada por Hax e Majluf (1996). Ainda que a Visão Baseada em Recursos tenha surgido em oposição aos princípios da Visão Baseada no Mercado, alguns autores vêm defendendo a existência de uma relação complementar dessas abordagens, visto que ambas procuram explicar o mesmo fenômeno de interesse - a sustentação da vantagem competitiva (SPANOS, LIOUKAS apud WALTER et al, 2005). Ao mesmo tempo, ambas conseguem servir uma a outra, de forma a preencher lacunas teóricas e práticas que cada uma delas sozinha não consegue lidar. 


\section{PLURALISMO TEÓRICO NA GESTÃO ESTRATÉGICA: A COMPREENSÃO DA VANTAGEM COMPETITIVA A PARTIR DA HARMONIZAÇÃO DE PERSPECTIVAS ANTAGÔNICAS}

Trabalhos mais recentes vêm considerando as duas abordagens como complementares para a compreensão dos motivos pelos quais as vantagens competitivas são criadas e sustentadas, possibilitando assim a definição de um modelo que observe equilibradamente tanto aspectos externos como internos às firmas. Para Barney (1991), a Visão Baseada em Recursos não substitui as ferramentas analíticas para o modelo das "cinco forças". Schoemaker (1990), Mahoney e Pandian (1992), e Foss (1996) apontam para a existência de complementaridade entre a estratégia competitiva de Porter e a Visão Baseada em Recursos, no sentido de que ambas buscam fornecer explicação sobre as condições que mantêm a vantagem competitiva e sobre o desempenho da empresa.

Foss (1996) argumenta que não existe dicotomia entre as abordagens e que o trabalho de Porter (1986) é em alguns aspectos até mesmo próximo aos insights da Visão Baseada em Recursos, porém, suas discussões são focadas nos determinantes da indústria, faltando qualquer análise profunda sobre os determinantes da firma, aspecto que é abordado pela Visão Baseada em Recursos. Nesse sentido, ambas as visões podem ser consideradas complementares.

Um modelo integrado, com a aplicação paralela de orientação para o mercado e para o interior da organização, segundo Mikus (apud WALTER et al., 2005), poderia permitir uma visão holística das alternativas que envolvem a concepção do planejamento estratégico, mesmo porque os objetos focados pelas duas teorias são diferentes. Barney (2002) observa que a união dos dois modelos se aproximaria, de forma simplista, da análise SWOT (Strenghts-Weakenesses-Opportunities-Threats), desenvolvida em 1960 por Andrews e Christensen (Porter, Montgomery, 1998), sendo que a Análise Estrutural da Indústria auxilia a análise de oportunidades e ameaças ambientais e Visão Baseada em Recursos contribui com a avaliação das forças e fraquezas das organizações.

Apesar de robusto, um modelo que integre essas duas abordagens permite apenas a identificação de forma conjunta interna e externamente dos aspectos que caracterizam a posição estratégica da empresa num determinado momento, sem considerar adequadamente a dinâmica dos ambientes competitivos, além de não tratar dos desafios enfrentados pelos gerentes para criar, gerir e manter as capacidades organizacionais. Ao considerando as semelhanças entre as duas teorias, percebe-se que ambas fundamentam-se nos pressupostos neoclássicos de comportamento econômico, racionalidade, estabilidade e previsibilidade dos mercados Heene e Sanchez (apud LEITE, PORSSE, 2003), logo, levam a explicações teóricas ex post dos ambientes competitivos e dos recursos importantes estrategicamente e apresentam capacidade limitada para fazer avaliações ex ante de resultados competitivos. Ossadnik (apud WALTER, 2005) pondera que a integração dos dois modelos representa apenas uma solução parcial para problemas de planejamento e decisões estratégicas, já que existe redução da complexidade na sua estruturação.

Para preencher tais lacunas e partindo da compreensão que a manutenção da vantagem competitiva ao longo do tempo está relacionada à capacidade da empresa em criar e recriar continuamente novas competências na medida em que mudam as características do ambiente de negócios, argumenta-se em favor de uma perspectiva que, além de integrar o modelo da Análise Estrutural da Indústria e da Visão Baseada em Recursos, agregue uma abordagem dinâmica, sistêmica, cognitiva e holística (HEENE, SANCHEZ apud LEITE, PORSSE, 2003), que possibilite concomitantemente a avaliação da contribuição dos recursos existentes para as oportunidades atuais e a capacidade de geração de novos recursos necessários para a obtenção de vantagem competitiva em ambientes futuros.

A Teoria das Capacidades Dinâmicas e a Teoria dos Processos do Mercado respondem justamente a essas necessidades desprezadas pelas teorias tradicionais. Ambas as teorias contribuem para a compreensão da origem e da manutenção da vantagem competitiva ao 
passo que agregam o conceito de capacidade dinâmica, conceituada como a habilidade da empresa de integrar, coordenar, construir e reconfigurar competências internas e externas (TEECE et al., 1997), e de desequilíbrio do sistema econômico (CONNER, 1991; KIRZNER, 1997). O foco na dinâmica da empresa, dos mercados e da concorrência implica aceitar a natureza dinâmica da vantagem competitiva.

Conseqüentemente, a habilidade da empresa para competir em seu mercado está ancorada na competência para identificar e compreender as forças competitivas do ambiente e as razões pelas quais elas se modificam de acordo com as circunstâncias e ao longo do tempo; e capacidade de criar e desenvolver competências para avaliar, decidir, implementar e acompanhar a estratégia competitiva escolhida e alinhar a ela todos os recursos à sua disposição (BARBOSA, 1999).

A proposta de um modelo pluralista para compreensão da vantagem competitiva, integrando as quatro perspectivas da teoria da estratégia descritas anteriormente busca, portanto, combinar a visão positivista, econômica, baseada na prescrição, racionalidade e na previsibilidade dos mercados, a uma perspectiva mais pragmática, que introduz a análise aspectos dinâmicos da empresa e do ambiente. Como cada uma das teorias, a sua maneira, visualiza o mesmo processo, em conjunto, acredita-se que podem auxiliar a uma compreensão holística, dinâmica e mais adequada a complexidade do mundo real.

\section{CONSIDERAÇõES FINAIS}

O presente trabalho procurou, a partir da análise da literatura acadêmica, discutir a possibilidade de construção de uma modelo que integre as quatro correntes principais de pesquisa em Gestão Estratégica que tratam da vantagem competitiva, quais sejam: a Análise Estrutural da Indústria, a Visão baseada em Recursos, a Teoria dos Processos de Mercado e a Teoria das Capacidades Dinâmicas.

Cada uma dessas abordagens procurar explicar a vantagem competitiva de forma divergente e fragmentada, sendo, ao mesmo tempo, interessante e criteriosa e, de certo modo, estreita e exagerada. Apesar de enriquecer a base do conhecimento em gestão estratégica, isoladamente, pouco contribui para interpretar as fontes de obtenção e de manutenção da vantagem competitiva e os motivos que levam algumas empresas a apresentam desempenhos superiores.

Para suprir as carências dessas visões e partindo do pressuposto que a manutenção da vantagem competitiva ao longo do tempo está relacionada à capacidade da empresa em criar e recriar continuamente novas competências na medida em que mudam as características do ambiente de negócios, argumenta-se em favor da estruturação de uma modelo pluralista e integrativo, que harmonize aspectos das quatro vertentes. Como as perspectivas priorizam diferentes focos de observação, um modelo integrativo viabilizaria uma análise mais equilibrada dos fatores que causam a vantagem competitiva, sejam estes externos ou internos à empresa.

No entanto, a pesquisa em estratégia parece não ter sido ainda capaz de propor tal estrutura integrada, devido à complexidade das quatro abordagens, que exige a consideração de múltiplos aspectos muitas vezes concorrentes entre as si.

Finalmente, este artigo sugere ferramentas para a conciliação de um modelo integrativo, focado especialmente na dinâmica da empresa, dos mercados e da concorrência, amparado no acolhimento da natureza dinâmica da vantagem competitiva, e esperando contribuir para investigações futuras sobre as origens da vantagem competitiva das empresas.

\section{REFERÊNCIAS}


AMIT, R.; ZOTT, C. Value creation in e-business. Strategic Management Journal, n. 22, 2001.

BAIN, J.S. Barriers to new competition. Cambridge: Mass, 1956.

BARBOSA, F.V. Competitividade: conceitos gerais. In: RODRIGUES, S. B. Competitividade, alianças estratégicas e gerência internacional. São Paulo: Atlas, 1999.

BARNEY, J. Firm resources and sustained competitive advantage. Journal of Managements v.7, n.1, p.99-120, 1991.

BRITO, L.A.L.; VASCONCELOS, F.C. de. A heterogeneidade do desempenho, suas causas e o conceito de vantagem competitiva: proposta de uma métrica. Revista de administração contemporânea, Rio de Janeiro, v. 8, n. S. Issue, p. 107-129, 2004.

CARNEIRO, J., CAVALCANTI, M.A., SILVA, J. Porter revisitado: análise crítica da tipologia do mestre. Revista de Administração Contemporânea, 1(3), 7-30, 1997.

CARNEIRO, J., CAVALCANTI, M. A., Silva, J. Porter revisitado: análise crítica da tipologia do mestre. Revista de Administração Contemporânea, 1997.

COLLINS, D.; MONTGOMERY, C. Competindo com base em recursos: estratégia na década de 1990. In: Estratégia corporativa. Rio de Janeiro, Campus, 2000.

CONNER, K.R. A historical comparison of resource based theory and five schools of thought within industrial organization economics: do we have a new theory of the firm? Journal of Management, v. 17, n. 1, p. 121-154, 1991.

D’AVENI, R.A. Hipercompetição: Estratégias para dominar a dinâmica do mercado. Rio de Janeiro, Campus, 1995.

EISENHARDT, K.M.; MARTIN, J. Dynamic capabilities: what are they? Strategic Management Journal 21 (Oct-Nov (special issue)): 2000, pp. 1105-1121.

FOSS, N. Research in Strategy, Economics, and Michael Porter. Journal of Management Studies, v. 33, p. 1-24, 1996.

GHEMAWAT, P. Commitment: the dynamic of strategy. New York: Free Press, 1991.

GRANT, R.M. The Resource-Based Theory of Competitive Advantage: Implications for Strategy Formulation. California Management Review, Vol. 33, n.3, p.114-135, 1991.

HAMEL, G.; PRAHALAD, C.K. Competindo pelo futuro: estratégias inovadoras para obter o controle do seu setor e criar os mercados de amanhã. Rio de Janeiro: Campus, 1995.

HAYEK, F.A.V. The road to serfdom. Chicago: The University of Chicago Press, 1944.

HAX, A.; MALUF, N.S. The Strategy Concept and Process. Englewood Cliffs, NJ: Prentice-Hall, 1991.

JACOBSEN, R. The persistence of abnormal returns. Strategic Management Journal, v. 9, p. 415-430, 1988.

KIRZNER, I.M. Entrepreneurial discovery and the competitive market process: an Austrian approach. Journal of Economic Literature, v. XXXV, p. 60-85, Mar. 1997.

LEITE, J.B., PORSSE, M. Competição baseada em competências e aprendizagem organizacional: em busca da vantagem competitiva. Revista de Administração Contemporânea, São Paulo, Edição Especial, p. 121-141, 2003. 
MASON, E.S. The current status of the monopoly problem in United States. Harvard Law Review, Vol.62, p.1265-1285, 1949.

PENROSE, E. The Theory of the Growth of the Firm. Oxford, UK: Oxford University Press, 1959.

PETERAF, M.A. The cornerstones of competitive advantage: a resource based view. Strategic Management Journal, 14, pp.179-191, 1993.

PORTER, M. Estratégia Competitiva: Técnicas para análise de indústrias e da concorrência. Rio de Janeiro: Campus, 1986.

PORTER, M.E. Como as forças competitivas moldam a estratégica. In: MONTGOMERY, C. A. PORTER, M. E. Estratégia: a busca da vantagem competitiva. Rio de Janeiro: Campus, 1998.

RUMELT, R.P.; SCHENDEL D.E.; TEECE, D.J. Fundamental Issues in Strategy. Harvard Business School Press, 1994.

SCHMALENSEE, R. Do markets differ much? The American Economic Review, v. 75, n. 3, p. 341-351, June 1985.

TEECE, D.J.; PISANO, G.; SHUEN, A. Dynamic capabilities and strategic management. Strategic Management Journal, v. 18, n. 7, p. 509-533, 1997.

VASCONCELOS, F.C.; BRITO, L.A.L. Vantagem competitiva: o construto e a métrica. Revista de Administração Brasileira, São Paulo, v. 44, n. 2, p. 51-63, abr. /jun. 2004.

VASCONCELOS, F.C.; CYRINO, A.B. Vantagem competitiva: os modelos teóricos atuais e a convergência entre estratégia e teoria organizacional. Revista de Administração de Empresas, v. 40, n. 1, p. 20-37, out./dez. 2000.

VOLBERDA, H.W. Crise em estratégia: fragmentação, integração ou síntese. Revista de Administração de Empresas - RAE, São Paulo: FGV, v. 44, n. 4, p. 32-43, Out./dez. 2004.

ZOLLO, M.; WINTER, S.G. Deliberate learning and the evolution of dynamic capabilities. Organization Science, n. 13, 2002.

WALTER, F., BANDEIRA DE MELLO, R., GÖTZE, U. A integração entre a visão baseada em recursos e a visão baseada no mercado da vantagem competitiva: dificuldades e perspectivas. Porto Alegre: Anais do XXV ENEGEP, 2005.

WERNEFELT, B.A. A resource-based view of de firm. Strategic Management Journal. v.5, p.171-180, 1984.

WINTER, S. Understanding dynamic capabilities. Strategic Management Journal, v.24, p. 991-995, 2003. 